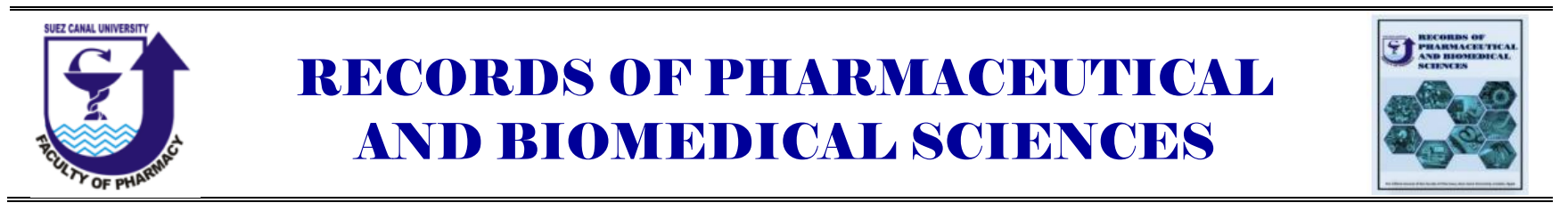

\title{
Pharmaceutical Counterfeit drugs: (The growing threat)
}

\author{
Mohamed A. Abdel Shakoura ${ }^{a}$, Randa A. Abdel Salam ${ }^{\text {b }}$, Ghada M. Hadad*b and Dina M. Abo-ElMatty

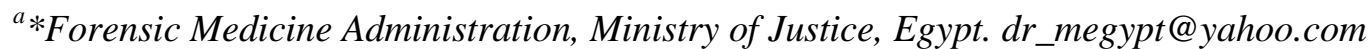 \\ ${ }^{b}$ Department of Pharmaceutical Analytical Chemistry, Faculty of Pharmacy, Suez Canal University, Ismailia, \\ Egypt. 41522, Egypt \\ ${ }^{c}$ Department of Biochemistry, Faculty of Pharmacy, Suez Canal University, Ismailia, Egypt.
}

\section{Received on: 15.12. 2018}

Revised on: 20. 01.2019

Accepted on: 25. 01. 2019

Correspondence Author:

Tel:+ 201221329641

E-mail address:

dr_megypt@yahoo.com

\begin{abstract}
The production of counterfeit or substandard drugs is a widespread problem which can no longer be ignored. The spread of counterfeit drugs not only in developing countries also it was detected in developed countries as well which may take part in morbidity, mortality, drug resistance, toxicity and loss of confidence in health-care systems. Moreover effort is urgently required on the legal, enforcement and scientific levels. Reliable analysis of the suspect products. Several means, essentially based on chromatography and spectroscopy, are now at the disposal of the analysts to enable the distinction between genuine and counterfeit products. However the determination of the components and the use of analytical data for forensic purposes still constitute a challenge. The aim of this review article is therefore to point out the intricacy of medicine counterfeiting and its impact so that a better understanding can provide solutions to fight more efficiently against it
\end{abstract}

Keywords: Counterfeit, analysis, threat.

\section{Introduction:}

Drugs are used to cure or treat disease, relieve symptoms, ease pain, prevent disease or symptoms, eliminate or reduce symptoms and to slow the disease process Counterfeit is something made for a dishonest purpose; an act deliberately designed to The World Health Organization defines counterfeit drugs as one which is deliberately and fraudulently mislabelled with respect to identify and/or source deceive (WHO, 1999).

Over the past decade, the massive public-health problem of counterfeit and substandard drugs has become increasingly apparent, causing significant morbidity and mortality and reducing the effectiveness of health care in the developing world (Newton et al, 2006).
The World Health Organization defines counterfeit drugs as one which is deliberately and fraudulently mislabelled with respect to identify and/or source . Counterfeiting of commercial products is an age old practice which flourishes in many countries and is motivated mainly by the huge profits to be made. Trade in counterfeit drugs appears to be widespread internationally, affecting both developed and developing countries. The spread of counterfeit drugs is generally more pronounced in those countries where the manufacture, importation, distribution, supply and sale of drugs are less regulated and enforcement may be weak. Counterfeiting can apply to both branded and generic products and counterfeit medicines may include products with the correct ingredients but fake packaging with the wrong ingredients, without 
active ingredients or with insufficient active ingredients (WHO, 2006).

Various countries and organizations use different definitions of counterfeit drugs (Wondemagegnehu,1999; Carpenter, 2006). One of the most widely used is that of the WHO (panel 1), where the emphasis is on the intent to deceive. A counterfeit drug can therefore contain the correct amount of active ingredient, as stated on the label, too much, too little, none at all, or the wrong ingredients. The amount of active ingredient is not sufficient information to determine whether a medicine is counterfeit. This judgment can only confidently be made by the additional inspection of the packaging. In many reports, whether a poor quality medicine is counterfeit or substandard is unclear (Shakoor et al., 1997). The distinction between the two categories is vital, since the reasons for their dissemination and potential counter measures are different. The circulation of substandard medicines in the developing world is a serious clinical and public health concern. Problems include under or over concentration of ingredients, contamination, poor quality ingredients, poor stability and inadequate packaging. Empirical observations have shown that there may be more fake than genuine drugs in circulation (WHO, 1999). Drugs which have been rejected by regulators or manufacturers may be sold in markets and are considered counterfeit (Wertheimer et al., 2003). The same holds true for drugs which have expired and have been relabelled with a fake later expiry date. Fake antibiotics with a low concentration of the active ingredients can cause damage by stimulating the development of drug resistance. According to the World Health Organization several factors encourage counterfeiters such as (WHO, 2010):

-Ineffective registration of medicines.

-High cost of genuine medicines, together with their desirability and shortage

-A large private sector health sector that is insufficiently regulated or where regulations are weakly enforced.

-Lack of knowledge of counterfeits and appropriate preventive measures, together with poor dissemination of information among health workers and the public.

-The lack of financial and human resources available to many drug regulatory authorities often makes effective recognition of poor quality drugs and action impossible.
-Places where most medicines can be bought without a prescription.

-Places where many people practice selfmedication.

-The shortage or erratic supply of medicine.

-Ineffective cooperation among different stakeholders.

-High levels of corruption.

-A poor population with little knowledge about health issues seeks out cheaper alternatives, thereby encouraging the spread of non-regulated outlet production and street-market or Internet distribution

-Globalization of the financial markets has facilitated the smuggling and illegal importing and exporting that are now widespread in some countries

-Rapid communications have boosted links between criminal networks.

\section{Counterfeit products may include:}

1. Products with the correct ingredients or the wrong ingredients.

2. Products with insufficient or no active ingredients.

3. Products with fake packaging.

4. Medicines with active ingredients different from what is stated on the package.

5. Expired medicines relabelled with the purpose to extend the shelf-life.

6. Products without the name and address of the manufacturer.

7. Expired products.

8. Drugs with no expiry date.

9. Medicines which do not contain any of the specified active ingredients despite what is written on the label.

10. Products which contain the correct strength of the specified active ingredient.

11. Products which contain the different quantity of impurities.

The problem is now worldwide and the networks involved are global. In 2007, counterfeits seized in Dubai were the result of a trade running from China through Britain, Hong Kong, Dubai, the United States and the Bahamas (Pagnamenta, 2007). Counterfeiting has become a structured industry with manufacturers, wholesalers, distributors and local sellers. The aim of counterfeiters is to complicate the market so that the traffic goes undetected (Roudaut, 2011). The Fig. 1 enables to observe where the counterfeits are generally produced and how they are distributed. 


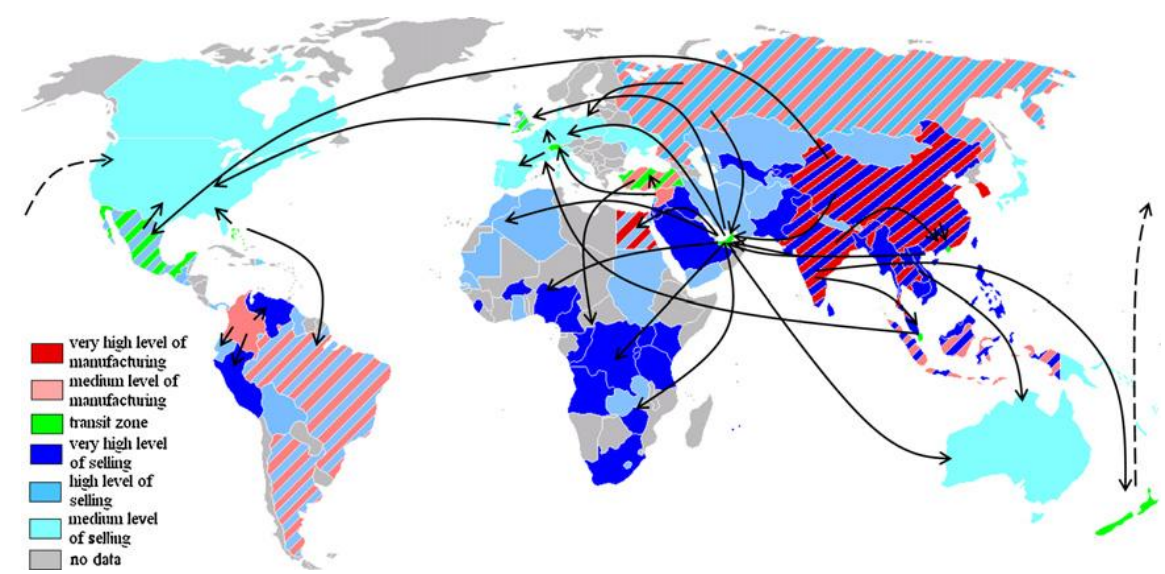

Fig. 1. Global repartition of medicine counterfeiting in the world - from production to selling.

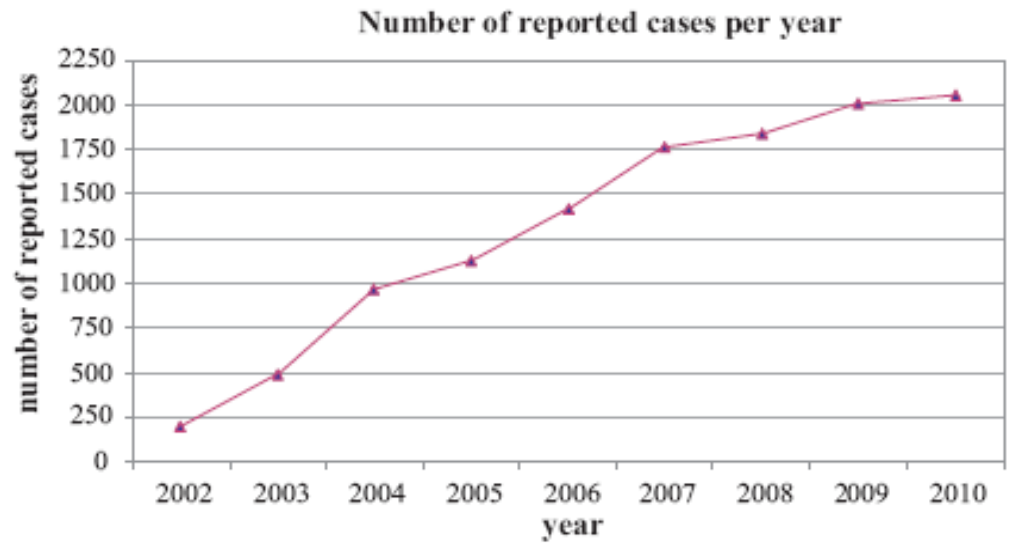

Fig. 2. Global increase in medicine counterfeiting between 2002 and 2010. Source: Pharmaceutical Security Institute.

Manufacturing appears concentrated in Asia (mostly India and China), where abundant and cheap workforce can be found, but also in Latin America (Roudaut, 2011). The United Arab Emirates play a central role (OECD, 2008). Other hubs include Central America and Switzerland (OECD, 2008; Newton et al., 2010, Clark, 2008). Counterfeit sales are massive in Africa and Asia, but also high in Latin America (EAASM, 2009). The number of reported counterfeit medicine cases seems to be rising (PSI, 2018) (Fig. 2). The Pharmaceutical Security Institute admits that these data may reflect increased awareness on the part of both the public and law enforcement authorities.

\section{Consequences and dangers of counterfeits}

The medicine may not be effective because it does not contain enough or even any active ingredient. The medicine may be dangerous because it contains too much of an active ingredient or contains other have been manufactured or stored in an uncontrolled environment that does not have the appropriate measures in place to ensure that medicines are safe and effective.

\subsection{Treatment failure}

Treatment failure and even death can result with the use of counterfeit drugs. Eliminating them is a considerable public health challenge. Defining the extent of counterfeiting is difficult for a number of reasons. Other associated health risks include antibiotic resistance (Green , 2006). The problem of fake and counterfeit drugs is very important in medicine because of the associated health risks. Therapeutic failure may be associated with the use of fake drugs containing insufficient or no active ingredient leading to loss of confidence by the patients. The situation is so bad that even when patients are treated with genuine antibiotics and antimalarial they no longer respond due to resistance induced previously by taking counterfeit 
unknown harmful ingredients. The medicine may

\subsection{End organ damage}

Ingestion of counterfeit drugs can result in damage to the liver, kidneys, heart and the central nervous system. The liver is responsible for breaking down drugs while the kidneys eliminate them from the body. When these poisons are taken into the body they can damage the vital organs.

\subsection{Toxicity}

Another important challenge is the management of target or most vulnerable groups of patients with high risk of toxicity or adverse effects and therapeutic failures which can lead to fatalities. They are the neonates, geriatrics (old people), pregnant women and those with reduced kidney or liver functions as well as the immunocompromised. The use of fake and counterfeit drugs in these patients would be catastrophic and absolutely clinically disastrous and mortality rates will be increased (Videau, 2006).

\subsection{False vital signs}

The use of fake and counterfeit drug can result in false values of vital signs.

\subsection{Death}

Disease sufferers are made to bear far greater burden than they ordinarily should and sometimes innocent lives are lost due to the scourge of fake and counterfeit pharmaceutical products. Thousands of people die each year after taking drugs that contained useless and harmful ingredients. Ineffectiveness of the counterfeit products leads to steady progression of the disease which eventually results in death. Lifesaving drugs have also been detected to be counterfeited.

\subsection{Loss of confidence}

Therapeutic or adverse events results in loss of confidence in the health system and the system of drug control and enforcement. The reputation of the original product is damaged and the pharmaceutical companies which invest huge resources in the developing innovative products suffer financially. Patients may lose confidence in the health care professionals.

\subsection{Economic loss:}

Economic loss as a result of drug counterfeiting is enormous. Many pharmaceutical companies lose large amounts of money because their products are being counterfeited and sold at cheaper rates. Drug therapy has financial implications both on the individual and the national economy. When the wrong drug or counterfeit is used it is waste and when excess or under dose of the right drug is used, it is also wasteful. It affects the individual finances because there is an increased cost of therapy. Man and fake drugs.

hours are also lost to illnesses that would have resolved much earlier if the right drugs were taken (Wertheimer et al.,2003).

\section{Intervention of the phenomenon}

There is clearly no simple solution to the problem of counterfeits, but much more could be done now to improve this enormous yet neglected problem that affects particularly the poorest, most vulnerable people. Several interlinked strategies are required, the success of which will depend greatly on increased information sharing and cooperation both within and between countries

\section{Increasing awareness}

Medicine counterfeiting is not new but it was only in the late 20th century that governments addressed the problem and conferences began to take place. In 1985 the WHO organized a conference in Nairobi that first drew attention to the issue (Chinwendu, 2008) The declaration of Rome resulted in 2006 in the creation of IMPACT, which brings together 193 member states and organizations such as Interpol (MEDIFAKE, 2008). The American Food and Drug Administration (FDA) and the European Medicines Agency (EMEA) also play a role in the fight against counterfeit medicines (IPR, 2010). Some countries have their own anti-counterfeiting institutions, such as the Medicines and Healthcare Products Regulatory Agency in the UK (Clark, 2008) and the Egyptian ministry of health.

Companies, public institutions, governments and law enforcement agencies should clearly work closely together to show an interest in fighting the problem and to perceive medicine counterfeiting as a branch of organized crime. However the market remains largely hidden, despite the occasional impressive seizures. The response needs to take its cue from the threat it is facing: it needs to be rapid, reactive, and globalized. Dedicated international cooperation is required to fight together against counterfeiting and other forms of criminality, especially in the legal field.

\section{Product protection}

Over the past few years manufacturers have been introducing new techniques for protecting their products. The first step is to secure the supply chain in all companies producing the raw materials that go into a medicine. This involves tightening internal security so that thefts are avoided (IMPACT, 2008).

The banknote and security document industry have been successful in introducing passive and active 
forms of protection. What medicines need are features that are simple and easy for the public to detect, semi-secret for pharmacists and hospitals, and fully secret for manufacturers. Such multilayered protection is effective in that it becomes expensive and difficult to reproduce for counterfeiters.

Among other approaches, the packaging or even the medicine itself can be coded and marked including 2D barcodes and standardized numerical identification, is increasingly implemented, as well as radiofrequency identification tags (RFID) . Research is carried out continuously to provide manufacturers with sophisticated cover features like taggants and nanoencryption [Shepherd, 2011; Mullard, 2010).

\section{Analytical techniques used in counterfeit analysis}

In the meantime the pharmaceutical industries and agencies keep improving their analytical methods with reliable techniques. Data from the chemical and packaging study can provide an insight into the phenomenon at different levels.

Suitable analytical methods should first allow the distinction between genuine products and counterfeits. This information needs to be as quick as possible in order to speed up the management of the suspect counterfeit case on a local basis. Indeed if a counterfeit is confirmed, the company and authorities need to act as soon as possible. Screening usually begins with rapid visual inspection. The package is then studied in detail, and the content of the suspect medicine is compared with genuine products. Analyses of packaging items, like boxes, blisters, vials and leaflets, consist for instance in the study of batch data, printing, holograms and logos.

The physical characteristics of the medicines, like their weight, shape, color or aspect, can then be evaluated and compared with references. Chemicophysical tests, consisting for instance in colorimetry (Rodomonte et al., 2010), dissolution tests (Kaur et al., 2010) or simple density or viscosity measurements (Al-Hussaini, 1996) are cheap and quick methods that sometimes prove very effective. However these tests often suffer from a lack of specificity and do not provide much information about the content.

Time being a crucial factor for the detection of counterfeits, the use of vibrational spectroscopy for solid suspect counterfeits has increased within the last years. Mid-Infrared (MIR) (Deconinck et al., 2011), Near Infrared (NIR) [Storme-Paris et al., 2009) and Raman spectroscopy (Trefi et al., 2008) enable measurements and interpretation of the results within minutes. The spectra can be directly overlaid and compared or chemometrics can help identify the spectrum of the suspect counterfeit within the database. Vibrational spectroscopy is indeed commonly associated to chemometric techniques combining mathematical pretreatments, classification methods and regression methods to interpret complex spectra. Further fast analytical tools have been recently investigated for counterfeit detection and may offer new avenues, like X-ray powder diffraction (Maurin et al., 2007), Ion Mobility Spectrometry (Likar et al., 2011), Direct Analysis in Real Time (DART) and Desorption Electrospray Ionization (DESI) MS (Likar et al., 2011) or MS associated to isotope

characterization (Santamaria et al., 2009). A conclusion about the genuineness of the product, including both packaging and dosage form analyses, can then be drawn. If the product is declared genuine, the case is closed. However if a counterfeit has been identified, further chemical analyses have to be performed.

Chemical analysis methods such as high performance liquid chromatography (HPLC) and gas chromatography coupled with optical, electrochemical, or mass spectrometric detectors have been the mainstays of pharmaceutical analysis. Gas chromatography has been particularly useful for detecting residual solvents, volatile constituents, and undeclared ingredients, whereas HPLC has been used for non-volatile chemicals eg, adulterants and organic residues (Phillips, 2003).

In financially poor countries where the proliferation of counterfeit drugs substantially affects public health, the provision of affordable and simple field detection methods is crucial until circumstances allow for a more in-depth forensic investigation of the suspected pharmaceuticals. Thin-layer chromatography (TLC) is a specifi c, sensitive, and inexpensive technique available for most common pharmaceuticals(Kenyon et al., 1994) and a TLC kit, the MiniLab (German Pharma Health Fund, Oberursel, Germany), has been developed specifically to allow analysis of essential medicines in the tropics (Jaehnke, 2004).

Colourimetry identifies particular active ingredients by making use of colour changes produced by chemical reactions or complexations between the active ingredient and a specific reagent. Quantitative measurements of active ingredient concentration as a function of colour intensity can then be made with a simple handheld photometer. Colourimetry does not necessarily 
require flammable or toxic organic solvents and can be done by untrained personnel.

Characteristic physical and chemical propertieseg, weight, density, refractive index, viscosity, osmolarity, $\mathrm{pH}$, crystal morphology, and solubility - can also be used to identify counterfeits[38]. Rugged, inexpensive, and portable handheld refractometers can be used to measure the refractive index of a solution and hence estimate the amount of a particular active ingredient present (Green et al., 2015; Cheung et al. 1991; Larkin, 2002; Green, 2006]. Since refractive index can only be used to measure the amount of dissolved active ingredients, the addition of simple qualitative colourimetric technique to confi $\mathrm{rm}$ the presence of a particular active ingredient produces an accurate and simple field assay.

The FDA's final report in 2004 identified 6 areas that require combined public and private measures to be successful in preventing counterfeit medicines. The 6 critical areas are as follows [FDA, 2004]:

-Securing the actual drug product and its packaging; -Securing the movement of the product as it travels through the U.S. drug distribution chain;

-Enhancing regulatory oversight and enforcement; -Increasing penalties for counterfeiters;

-Heightening vigilance and awareness of counterfeit drugs; and

-Increasing international collaboration.

The FDA is encouraging the industry for voluntary adoption of the technology.

The FDA also recommends:

-Use of authentication technologies for pharmaceuticals, which have been sufficiently perfected so that they can now serve as a critical component of any strategy to protect products against counterfeiting. Authentication technologies include inks, holograms, tags, chemical markers, and other technologies that might develop over time.

-Adoption and enforcement of strong, proven anticounterfeiting laws and regulations by states.

-Working with the National Association of Boards of Pharmacy in its efforts to develop and implement revised state rules for licensure of wholesaler drug distributors.

- Increased criminal penalties to deter counterfeiting and more adequately punish those convicted.

-Adoption of secure business practices by all participants in the drug supply chain.

- Development of a system that helps ensure effective reporting of counterfeit drugs to the

\section{Conclusion:}

agency and that strengthens FDA's rapid response to such reports.

-Creation of a Rapid Alert System (RAS) precisely to add to the necessity of a quick response when a counterfeit is suspected.

- Education of consumers and health professionals about the risks of counterfeit drugs and how to protect against these risks.

-Collaboration with foreign stakeholders to develop strategies to deter and detect counterfeit drugs globally. In 2005, the WHO developed the "Rapid Alert System" (RAS), a mechanism serving as a rapid alert for WHO member states and partner organizations for combating counterfeit drugs in the Western Pacific Region. When counterfeit medicines are detected in the region and reported through the RAS, relevant authorities are alerted immediately and actions are taken (WHO, 2005). The WHO has developed the WHO Certification Scheme on the quality of pharmaceutical products to assist countries ensure the quality of imported products. The features of the Certification Scheme include actions at the national and international levels to fight counterfeit medicines:

- Appropriate legislation and penal sanctions: a clear legal definition of counterfeit medicines is needed and also sanctions that fit the crime.

- International harmonization: at present even the definition of a counterfeit medicine varies from country to country.

- Sufficient administrative and regulatory capacity: coordination action at the local level between health authorities, police, customs, and judiciary institutions to ensure proper regulation, control, investigation, and prosecution.

- International information networks: to monitor the traffic of goods, exchange information, issue alerts from country to country.

- Streamlined distribution channels: to ensure effective monitoring of manufacture, importation, and distribution of medicines. International monitoring of "extraterritorial" zones: at present these are excluded from normal regulatory oversight.

- Evaluation of medicine prices: excessive price gaps or extremely high prices, may lead to people to seek cheaper alternatives.

- Increased public information: patients, dispensers, and doctors have a right to know if there are suspect goods on the market and the risks involved. - Low- or high-tech solutions: technology can accelerate lengthy legal and administrative processes to provide faster solutions.

active ingredient, because of high temperatures and humidity of storage, where the amount of active 
Trade in counterfeit drugs appears to be widespread internationally and affects both developing and developed countries. The spread of counterfeit drugs is generally more pronounced in countries where the manufacture, importation, distribution, supply and sale of drugs are less regulated and enforcement may be weak. To achieve the goal of health for all, the menace of counterfeit drugs needs to be controlled. Counterfeit medicine poses a serious threat to public health and has taken a silent devastating toll on humanity due to the lack of reporting in some critically affected areas. In addition to past and present losses due to fake drugs, the future of global health is at risk. Disease causing agents can develop resistance to genuine drugs

Medicines must be safe, effective and of acceptable quality and should be used rationally in order to produce the desired effects with good clinical and therapeutic outcomes. Part of the reason for the poor quality of drugs is due to decomposition of the

\section{References}

Al-Hussaini, S.R., 1996. Counterfeit captagon: an analytical study. Sci. Just. 36, 139-142.

Carpenter J, 2006. US Pharmacopeia. A review of drug quality in Asia with focus on anti-

infectives.

http://www.uspdqi.org/pubs/other/ANEReview. pdf

Cheung, J.F., Chong, S., Kitrenos , J. G., Fung, H., 1991. Use of refractometers to detect controlled-substance tampering. Am. J. Hosp. Pharm., 48, 1488-92.

Chinwendu, O, 2008. (NAFDAC), The fight against fake drugs by NAFDAC in Nigeria, NAFDAC Journal (Nigerian National Agency for Food, Drug Administration and Control), http://apps.who.int/medicinedocs/documents/s184 $\underline{05 \mathrm{en} / \mathrm{s} 18405 \mathrm{en} . \mathrm{pdf}}$

Clark, E., 2008. Counterfeit Medicines: the Pills That Kill, Telegraph, http://www.telegraph.co.uk/health/3354135/Count erfeit-medicines-thepillsthat-kill.html Deconinck, E., Sacré, P.Y., Coomans, D., De Beer, J., 2011. Classification trees based on infrared spectroscopic data to discriminate between genuine and counterfeit medicines. J. Pharm. Biomed. Anal., 57, 68-75. drug is well below stated amounts. Use of these preparations could lead to therapeutic failure. Fake and poor quality drugs are rife in developing countries and are costing lives. The illicit trade in counterfeit drugs remain a great threat to the lives of people.

All drugs should be labelled in a language that is easily understood. The label on each individual container should at least contain the pharmacological name, batch number, dosage form, strength, formulation, name of manufacturer, quantity in the container, storage conditions, route of administration and expiry date. Drugs should be obtained from a reliable source and comply with quality standards in the country. The only way for one to regain one's health is to take medications as prescribed by the doctor. Counterfeit drug is a major challenge to quality health care with devastating health, socio-economic and image effects on the citizenry.

European Alliance for Access to Safe Medicines (EAASM), 2009. The Counterfeiting Superhighway, Medicom Group Ltd., Hampton Court, UK, http://v35.pixelcms.com/ams/assets/312296678531 1455EAASMcounterfeiting\%20report 020608.pdf

European Union, Customs Millions of Illegal Medicines Stopped by MEDIFAKE Action, European Union press release, 2008, http://europa.eu/ rapid/pressReleasesAction.do?reference=IP/08/19 80\&format $=$ HTML\&aged $=$ $\underline{0 \text { \&language }}=\mathrm{EN} \&$ guiLanguage $=\mathrm{en}$

FDA. Combating counterfeit drugs: a report of the Food and Drug Administration. Available at: http://

www.fda.gov/oc/initiatives/counterfeit/report02_0 4. html.

Geneva: WHO.

Green, M. D., Nettey, H., Rojas, O. V., Pamanivong, C., Khounsaknalath, L., Grande Ortiz, M., Newton, P.N.., Fernández, F. M., Vongsack , L., Manolin, O., 2006. Use of refractometry and colorimetry as field methods to rapidly assess antimalarial drug quality. J Pharm Biomed Anal 43(1),105-110. 
Green, M.D., Hostetler, D.M., Nettey, H., Swamidoss, I., Ranieri, N., Newton, P.N., 2015.Integration of novel low-cost colorimetric, laser photometric, and visual fluorescent techniques for rapid identification of falsified medicines in resource-poor areas: application to artemether-lumefantrine. Am. J. Trop. Med. Hyg., 92, 8-16.

Green, M.D.,2006. Antimalarial drug resistance and the importance of drug quality monitoring. J. Postgrad. Med., 52, 288-90.

International Medical Products AntiCounterfeiting Taskforce (IMPACT), 2008 Counterfeit Drugs Kill!, World Health Organization, Geneva, Switzerland, http://www.who.int/impact/FinalBrochureWHA20 08a.pdf

Interpol, Intellectual Property Rights (IPR) Programme, 2010. http:// www.interpol.int/public/financialcrime/intellectual property/default.asp

Jaehnke, R.W., 2004. Counterfeit medicines and the GPHF-Minilab for rapid drug quality verification. Pharm. Ind. 66, 1187-93.

Kaur, H., Green, M.D., Hostetler, D.M., Fernandez, F.M., Newton, P.N., 2010. Antimalarial drug quality: methods to detect suspect drugs. Future Med., 7, 49-57.

Kenyon, T.A., Kenyon, A.S., Sibiya T., 1994. Drug quality screening in developing countries: establishment of an appropriate laboratory in Swaziland. Bull. World Health Organ., 72, 61520.

Koczwara, A., Dressman, J., 2017. Poor-Quality and Counterfeit Drugs: A Systematic Assessment of Prevalence and Risks Based on Data Published From 2007 to 2016. J. Pharm. Sci., 106, 29212929.

Larkin, M., 2002. Hand-held device detects fake drugs. Lancet Infect. Dis. 2, 5.

Likar, M.D., Cheng, G., Mahajan, N., Zhang, Z., 2011. Rapid identification and absence of drug tests for AG-013736 in $1 \mathrm{mg}$ Axitinib tablets by ion mobility spectrometry and DARTTM mass spectrometry. J. Pharm. Biomed. Anal., 55, 569573.
Maurin, J.K., Plucinski, F., Mazurek, A.P., Fijalek, Z., 2007. The usefulness of simple X-ray powder diffraction analysis for counterfeit control - the Viagra ${ }^{\circledR}$ example. J. Pharm. Biomed. Anal., $43,1514-1518$.

Mullard, A., 2010 The anticounterfeiter's technological tool kit. Nat. Med., 16361.

Newton, P.N, Green, M. D., Fernández, F.M. Day, N. P. J.. White, N. J, 2006. Counterfeit antiinfective drugs. Lancet Infect. Dis, 6, 602-13.

Newton, P.N., Green, M.D., Fernández, F.M., 2010. Impact of poor-quality medicines in the 'developing' world. Trends Pharmacol. Sci., 31,99-101.

Organisation for Economic Co-operation and Development (OECD), The Economic Impact of Counterfeiting and Piracy, OECD, Paris, France, 2008, $\quad$ p. 397 http://www.oecdbookshop.org/oecd/display.asp?la $\underline{\text { ng}}=$ EN\&sf $1=$ identifiers \& st $1=9789264045521$

Pagnamenta, R., 2007. Fake World of the Viagra Plotters, Times, London, UK, http://www.timesonline.co.uk/tol/life and style/health/article2477868.ece （accessed 07.12.12).

Pharmaceutical Security Institute (PSI),2018 Counterfeit Situation, Washington, DC, http://www.psi-inc.org/counterfeitSituation.cfm

Phillips, G., 2003. World Congress of Pharmacy and Pharmaceutical Sciences: anticounterfeiting measures. Pharm. J., 271, 465.

Rodomonte, A. L., Gaudiano, M.C., Antoniella, E., Lucente, D., Crusco, V. , Bartolomei, M. , Bertocchi, P., Manna, L., Valvo, L., Muleri, N., 2010. Counterfeit drugs detection by measurement of tablets and secondary packaging colour. J. Pharm. Biomed. Anal., 53, 215-220.

Roudaut, M.R., 2011 Contrefac, on: un crime invisible (Counterfeit: an invisible crime), Cahiers de la Sécurité, 5, 25-35.

Santamaria-Fernandez, R., Hearn, R., Wolff, J.C., 2009. Detection of counterfeit antiviral drug HeptodinTM and classification of counterfeits using isotope amount ratio measurements by multicollector inductively coupled plasma mass 
spectrometry (MC-ICPMS) and isotope ratio mass spectrometry (IRMS). Sci. Just., 49, 102-106.

Shakoor O., Taylor R. B., Behrens R. H., 1997. Assessment of the incidence of

substandard drugs in developing countries. Trop Med Int Health. 2, 839-45.

Shepherd, M., 2011. Worldwide landscape of counterfeit drugs, in: $35^{\text {th }}$ Annual Eastern Medicaid Pharmacist Administrators Association (EMPAA),

http://www.empaa.org/downloads/EMPAA2011/pr esentation/ ShepherdMary Counterfeit Drugs EMPAA2011.pdf.

Storme-Paris, I., Rebiere, H., Matoga, M., Civade, C. , Bonnet, P.A., Tissier, M. H., Chaminade, P., 2009. Challenging near infrared spectroscopy discriminating ability for counterfeit pharmaceuticals detection. Anal. Chim. Acta, 658,163-174.

Trefi, S., Routaboul, C., Hamieh, S., Gilard, V., Malet-Martino, M. Martino, R., 2008. Analysis of illegally manufactured formulations of tadalafil (Cialis ${ }^{\circledR)}$ ) by $1 \mathrm{H}$ NMR, 2D DOSY $1 \mathrm{H}$ NMR and Raman spectroscopy. J. Pharm. Biomed. Anal., 47, 103-113.

Videau, J.Y., 2006. Quality of medicines in least developed countries. Med. Trop., 66, 533-7.
Wertheimer, A. I., Chaney, N. M. , Santella, T., 2003. Counterfeit pharmaceuticals: current status and future projections. J. American. Pharm. Assoc., 43, 710-18.

WHO Regional Office for the Western Pacific, Essential Drug Medicines Policy. Available at: http://www.

wpro.who.int/NR/rdonlyres/C7BFA66C-64CF-

4109- 9254 484FE520D944/0/EDMP_June05.pdf.

WHO. 1999 Guidelines for the development of measures to combat counterfeit drug. http://www.who.int/medicines/publications/counte rfeitguidelines/en/

Wondemagegnehu, E., 1999 Counterfeit and substandard drugs in Myanmar and Viet Nam. WHO Report. WHO/EDM/QSM/99.3.

World Health Organization Fact Sheet 272. Revised 2006 February. Http:// who.int/mediacentre/factsheets/fs27 5/en/

World Health Organization, Medicines: Counterfeit Medicines, WHO Fact Sheet 275, WHO, Geneva, Switzerland, 2010 http://www.who.int/ mediacentre/factsheets/fs275/en/index.html. 